\title{
Factors Affecting the Prevalence of Obesity Among Primary School Students in Turkey
}

\author{
Tulay Kuzlu Ayyildiz ${ }^{1}$; Meltem Kurtuncu ${ }^{1,} ;$ Hulya Kulakci $^{2}$; Sevim Celik $^{2}$ \\ ${ }^{1}$ Department of Pediatric Nursing, Bulent Ecevit University, Zonguldak, Turkey \\ ${ }^{2}$ Department of Nursing, Bulent Ecevit University, Zonguldak, Turkey \\ ${ }^{*}$ Corresponding Author: Meltem Kurtuncu, Department of Pediatric Nursing, Bulent Ecevit University, Zonguldak, Turkey. Tel: +90-3722613394, Fax: +90-3722613399, E-mail: meltem- \\ kurtuncu@yahoo.com
}

Received: January 22, 2014; Revised: April 7, 2014; Accepted: September 2, 2014

\begin{abstract}
Background: Obesity is an energy metabolism disorder which results in the excessive storage of fat and may also lead to physical and psychological problems. Since the 1980s, obesity has drastically increased across all age and socio-economic groups around the world. Objectives: The purpose of the study was to investigate the risk factors affecting obesity in students in the age group of 6-15 years. Patients and Methods:This was a population-based cross-sectional study on 868 students in Bahçelievler elementary school in Zonguldak, Turkey from March to April in 2010. Data was collected using demographic questionary forms and weight-length measurements.

Results: The median age was $10.3 \pm 2.1 ; 47.6 \%$ of the children were female and $52.4 \%$ of them were male. About $70.2 \%$ of the students consumed fast food. It was identified that $67.1 \%$ of the students in the 6-10-year age group and $32.9 \%$ in 11-15-year age group were obese (P $=0.000)$. The obesity prevalence of children with one or two siblings was higher than the ones with more than two siblings $(\mathrm{P}=0.001)$. Conclusions: The study concluded that there were certain criteria related to development of obesity during a specific period of childhood and taking certain precautions could be effective in preventing it.
\end{abstract}

Keywords:Body Mass Index; Children; Obesity; Health Behavior

\section{Background}

Obesity is an energy metabolism disorder which results in the excessive storage of fat and may also lead to physical and psychological problems $(1,2)$. Since the 1980s, obesity has drastically increased across all age and socioeconomic groups around the world. In the United States, the proportion of overweight adults is $54.9 \%$ and obese adults is $22.3 \%(3,4)$. In 2006, the World Health Organization reported more than 400 million obese and 1.6 billion overweight people in the world and it is estimated that these numbers will reach 700 million and 2.3 billion, respectively, by 2015. The obesity rates are increasing due to factors such as malnutrition, insufficient physical activity, age, gender, education, income, race, socio-cultural structure, genotype, stress, depression, smoking, alcohol consumption, medicines usage, increase in births per woman and the timing between these births. This literature emphasizes that variables such as income, gender, occupation, marital status, food cost, architecture of cities, the labor force on females, and urbanization affect obesity (5).

In today's society, the prevalence of obesity is not only limited to developed countries but also has begun to become an issue in developing countries (6). As a developing country itself, Turkey's obesity rates have been increasing among adults. The rate of obesity is $21.2 \%$ among males and $41.5 \%$ among females (7). Considering that obesity has become more frequent among adults, and especially its even higher prevalent among children in recent years, this epidemy has taken the lead as the number one health problem (8). Research studies have determined that children commonly have a dietary lifestyle containing too much sugar, fat, or fast food (6). In the etiology of obesity, psychological conditions, genetic factors, sedentary life-style, nutritional habits, socio-economic status, endocrinal defects, and the use of drugs all play a role in the onset of poor nutrition and subsequent occurrence of obesity $(2,6)$. The prevalence rates of overweight and obese children have also been rapidly increasing, raising the risk of heart disease, hyperlipoidemia, Type-2 diabetes, and hypertension $(5,7)$.

Therefore, on behalf of creating a healthy society, the prevention of obesity in children is one of the important fields in terms of health services. In this research, to attain a successful conclusion, it is important to create a group of students from the school population. The school health services have been able to control the health risks at every level and have had an important role in helping students adopt healthy lifestyle behaviors (9). In addition to the normal role and function of the school nurses, due to different and complicated needs of the environment, 
they are serving and, as this environment are far medical solution opportunities, the frequency and quality of their roles can change accordingly (10). Because they help with finding solutions, acting as an advisor and offering an efficient response to problems arising during this process, school nurses are thought to be essential in the fight against obesity.

\section{Objectives}

The purpose of this study was to investigate the frequency of obesity and the factors affecting it in children 6-15 years old, who are students of Bahcelievler elementary school in Zonguldak, Turkey.

\section{Patients and Methods}

\subsection{Design and Sample}

This was a population-based cross-sectional study. All the primary school students $(n=12939)$ who were part of the study population were from the central Zonguldak province, Turkey. Population $\mathrm{a}=0.05$ and $\mathrm{p}=\mathrm{q}=0.5$ were taken; thus, the sampling size was calculated as 374 . Bahcelievler elementary school was chosen with a simple random sampling method. The sample group lasted from March to April 2010, including students who attended Bahcelievler elementary school in Zonguldak, Turkey, but were without any medical diagnoses, chronic conditions or under any prescriptions. A total of 186 students were excluded, of which 180 did not meet the inclusion criteria and six did not agree to be part of the study. Of the 1054 students of Bahcelievler elementary school, 868 students were included who met the study criteria and agreed to be part of the study.

\subsection{Data Collection Tools}

\subsubsection{Preparation of Data Collection Form}

The data collection format was prepared through analyzing the related literature $(6,8)$. A preapplication was reviewed with 10 children and it was then rearranged with respect to their opinions to test the format intelligibility and function. Afterwards, the format was finalized. These 10 children were excluded from the target study population. A data collection form with 26 questions determined the children's demographical specificities (age, genetics, family education, family social situation, etc.) as well as the risk factors affecting them in developing obesity (height, weight, nutritional specifications).

\subsubsection{Administration of the Data Collection Question- naire}

The children's information were filled during a face-toface meeting. Questions targeting the children's families were sent to their home and returned. Using body mass index (BMI) to measure obesity is practical and the most widely accepted method today. Weight $(\mathrm{kg})$, height (m), and rate of increase $\left(\mathrm{BMI}=\right.$ weight $(\mathrm{kg}) /$ height $\left.^{2}\left(\mathrm{~m}^{2}\right)\right)$ were measured. BMI varies among children depending on their age and genetics, according to which the BMI percentile is determined. According to this table, those in the 95th percentile were evaluated as obese (8).

In this study, the students' height and weight measurements were evaluated as follows: the students were measured by a tape measuring tool; they were barefoot, in a position of attention, feet together, with their back against a plain wall. Their heights were measured from head to foot. Weight measurements were taken by a researcher expertized on child health using a portable scale which was adjusted to zero on a plain surface. The measurements were taken before lunch break and students were told to avoid wearing any outfit other than their school uniform.

\subsection{Statistical Analysis}

Data were assessed using the SPSS 15.0 (SPSS Inc., Chicago, IL, USA) (11). Statistical analyses tools such as number, percentage, mean, and chi-square were used. The results were evaluated against a 95\% confidence interval and $\mathrm{P}<$ 0.05 was considered significant.

\subsection{Ethical Approval}

Permission for the research was obtained from the Ethics Committee of Medical Faculty of Zonguldak Karaelmas University prior to the study (Reg. No: 2010/01). The study protocol was specified. Upon the approval of the Provincial Directorate for National Education and Governorship of Zonguldak, the collaboration was created by informing the school director and teachers about the course of the study. Children who met the research criteria and their parents were informed about the aim, plan and benefits of the survey, were asked to fill out the patient information forms. Children and parents who accepted to participate in the survey signed patient consent forms and the survey started thereafter.

\section{Results}

The distributions of characteristic properties of the children are given in Table 1 . The students were 6-15 years old and the median age was $10.3 \pm 2.1 ; 47.6 \%$ of the children $(n=413)$ were female and $52.4 \%(n=455)$ were male; $8.5 \%(n=74)$ of the families had one child, $69.0 \%(n=599)$ of had $2-3$ and $22.5 \%(n=195)$ had four or more children. Regarding residency, $96.2 \%$ of the students $(n=835)$ lived in city centers and 3.2\% of them $(n=28)$ lived in the counties. The mean of scale measurements was $39.2 \pm 12.9$ (18$97 \mathrm{~kg}$ ) and the mean of length measurements was $140.7 \pm$ 
Ayyildiz TKet al.

$13.0(177-112 \mathrm{~cm})$.

Fast food consumption frequency of the children and distribution of their reasons for consuming fast food are given in Table 2. Of the students, 70.2\% $(n=609)$ consumed fast food; $60.5 \%$ of them $(n=451)$ consumed it just because they wanted to, $18.7 \%(n=164)$ because they are at school at lunch time, and $41.0 \%(n=359)$ because they want to be with their friends at the canteen. At the same time, $50.7 \%$ of the students $(n=309)$ consumed fast food when they were with their friends, 30.5\% $(n=186)$ in their spare times, and $10.1 \%(n=62)$ when they went out with their families on weekends.

The distribution of weight statuses according to sociodemographic attributes are given in Table 3. For BMI evaluation, the international BMI values that include overweight and obesity limits in accordance with age and gender were used (12). Of the students, $8.4 \%$ were overweight and 6.5\% were obese. In Table 3, the children's BMI positions were dependent on their socio-demographic specifications. Of the female students, $47.2 \%(n=76)$ were overweight and $36.4 \%(n=52)$ were obese; of the male students, 52.8\% ( $n=85)$ were overweight and 63.6\% $(n=91)$ was obese. There was a meaningful difference regarding gender $(\mathrm{P}<0.05)$. When the obesity levels were considered in accordance with age, $67.1 \%$ of the students in the 6-10 age group ( $n=96)$ and $32.9 \%$ in the $11-15$ age group ( $n$ =47) were obese. Children whose fathers were working (90.2\%), whose mothers were primary school graduates (30.8\%), who consumed fast food (72\%), and who had an obese member in the family (29.4\%) were more likely to be obese.

Table 1. Distribution of Children According to Their Characteristics $(\mathrm{n}=868)^{\mathrm{a}}$

\begin{tabular}{ll}
\hline Characteristic Properties & Value \\
\hline Gender & \\
\hline Male & $455(52.4)$ \\
\hline Female & $413(47.6)$ \\
\hline Age Group, $y$ & \\
\hline $6-10$ & $480(55.2)$ \\
\hline $11-15$ & $388(44.8)$ \\
\hline
\end{tabular}

\section{Residence}

\begin{tabular}{|lc|}
\hline City & $835(95.6)$ \\
\hline County & $28(3.6)$ \\
\hline Town & $5(0.8)$ \\
\hline Age,y & $10.3 \pm 2.1$ \\
\hline Scale weight, kg & $39.2 \pm 12.9$ \\
\hline Height, cm & $140.7 \pm 13.0$ \\
\hline
\end{tabular}

\begin{tabular}{ll} 
Body mass index & $19.4 \pm 4.0$ \\
\hline a Data are presented as No. (\%) or Mean \pm SD. &
\end{tabular}

It was identified that families of $33.5 \%$ of overweight students and $39.2 \%$ of obese students had a high income, which was considered 1500 Turkish Liras and above. Of the overweight children, $29.8 \%$ had one meal in addition to the three main meals and $31.5 \%$ of the obese students had two meals in addition; $88.8 \%$ of the overweight students regularly had breakfast, $75.2 \%$ of them regularly had lunch, and $95.7 \%$ regularly had dinner; $84.6 \%$ of the obese children regularly had breakfast, $76.2 \%$ of them regularly had lunch, and 90.9\% regularly had dinner. It was determined that 78.9 of the overweight students and $74.8 \%$ of the obese ones did not have a habit of eating at night.

Table 2. Fast Food Consumption Frequency of Children and Distribution of the Reasons $(\mathrm{n}=868)^{\mathrm{a}}$

Variables Value

\section{Fast food consumption} status

\begin{tabular}{|c|c|}
\hline Yes & $609(70.2)$ \\
\hline No & $259(29.8)$ \\
\hline
\end{tabular}

\section{Reasons of fast food consumption}

\begin{tabular}{|c|c|}
\hline I want to & $451(60.5)$ \\
\hline $\begin{array}{l}\text { There is no food pre- } \\
\text { pared at home }\end{array}$ & $23(3.6)$ \\
\hline $\begin{array}{l}\text { I do not like the food } \\
\text { prepared at home }\end{array}$ & $37(4.2)$ \\
\hline It is cheap & $24(3.8)$ \\
\hline $\begin{array}{l}\text { I am in school at lunch } \\
\text { time }\end{array}$ & $164(18.7)$ \\
\hline $\begin{array}{l}\text { My friends have fast } \\
\text { food }\end{array}$ & $359(41.0)$ \\
\hline
\end{tabular}

\section{Time of fast food con-} sumption $(\mathbf{n}=609)^{\mathrm{b}}$

They are with their
friends

Their spare time

They go out with their family on weekends

During exercising
$309(50.7)$

186 (30.5)

$62(10.1)$

$25(4.1)$ 
Ayyildiz TKet al.

\begin{tabular}{|c|c|c|c|c|c|c|}
\hline Between the meals & \multicolumn{2}{|c|}{$116(19.0)$} & \multicolumn{4}{|c|}{$\begin{array}{l}\text { a Data are presented as No.(\%). } \\
\text { b Children gave more than one answer to this question. }\end{array}$} \\
\hline Variables & Underweight $(<5 \%)$ & Normal (5-85\%) & Overweight (86-95\%) & Obese ( $\geq 96 \%$ ) & $\chi^{2}$ & PValue \\
\hline Gender & & & & & 12.052 & 0.007 \\
\hline Female & $15(68.2)$ & $270(49.8)$ & $76(47.2)$ & $52(36.4)$ & & \\
\hline Male & $7(31.8)$ & $272(50.2)$ & $85(52.8)$ & $91(63.6)$ & & \\
\hline Age, $y$ & & & & & 21.524 & 0.000 \\
\hline $6-10$ & $8(36.4)$ & $273(50.4)$ & $103(64)$ & $96(67.1)$ & & \\
\hline $11-15$ & $14(63.6)$ & $269(49.6)$ & $58(36)$ & $47(32.9)$ & & \\
\hline Number of siblings & & & & & 22.778 & 0.001 \\
\hline The only child & $0(0)$ & $33(6.1)$ & $23(14.3)$ & $18(12.6)$ & & \\
\hline 1 or 2 siblings & $16(72.7)$ & $370(68.3)$ & $114(70.8)$ & $99(69.2)$ & & \\
\hline 3 or more & $6(27.3)$ & $139(25.6)$ & $24(14.9)$ & $26(18.2)$ & & \\
\hline $\begin{array}{l}\text { Occupation of } \\
\text { father }\end{array}$ & & & & & 12.478 & 0.006 \\
\hline Retired & $6(27.3)$ & $43(7.9)$ & $9(5.6)$ & $14(9.8)$ & & \\
\hline Working & $16(72.7)$ & $499(92.1)$ & $152(94.4)$ & $129(90.2)$ & & \\
\hline $\begin{array}{l}\text { Education level of } \\
\text { mother }\end{array}$ & & & & & 28.995 & 0.016 \\
\hline $\begin{array}{l}\text { She could read and } \\
\text { write }\end{array}$ & $1(4.5)$ & $4(0.8)$ & $0(0)$ & $1(0.7)$ & & \\
\hline $\begin{array}{l}\text { Primary school } \\
\text { graduate }\end{array}$ & $12(54.5)$ & $196(36.2)$ & 5131.7() & $44(30.8)$ & & \\
\hline $\begin{array}{l}\text { Secondary school } \\
\text { graduate }\end{array}$ & $1(4.5)$ & $81(14.9)$ & $29(18)$ & $24(16.8)$ & & \\
\hline $\begin{array}{l}\text { High school gradu- } \\
\text { ate }\end{array}$ & $5(22.7)$ & $158(29.2)$ & $50(31.1)$ & $39(27.3)$ & & \\
\hline $\begin{array}{l}\text { Post-secondary } \\
\text { graduate or higher }\end{array}$ & $3(13.6)$ & $103(19)$ & $31(19.3)$ & $35(24.5)$ & & \\
\hline $\begin{array}{l}\text { Fast food consump- } \\
\text { tion }\end{array}$ & & & & & 8.322 & 0.04 \\
\hline Yes & $19(86.4)$ & $364(67.2)$ & $123(76.4)$ & $103(72)$ & & \\
\hline No & $3(13.6)$ & $178(32.8)$ & $38(23.6)$ & $40(28)$ & & \\
\hline $\begin{array}{l}\text { Family history of } \\
\text { obesity }\end{array}$ & & & & & 51.099 & 0.01 \\
\hline Yes & $3(13.6)$ & $42(7.7)$ & $32(19.9)$ & $42(29.4)$ & & \\
\hline No & $19(86.4)$ & $500(92.3)$ & $129(80.1)$ & $101(70.6)$ & & \\
\hline
\end{tabular}

a Data are presented as No.(\%).

\section{Discussion}

With the changing circumstances, such as consumption of high-energy foods and ever-decreasing physical activity, obesity has become an important health issue of industrialized countries. Socioeconomic conditions, environment, nutrition and demographic structures are factors that lead to the development of obesity. When in- dustrialized Sweden and the US are compared, the prevalence of obesity in the US is two times more than Sweden due to cultural differences. Obese children of the US are of particular concern. According to the results of the studies in Turkey, obesity prevalence in pre-school children has been $2.2 \%$ (13). 
Simsek et al. (14) determined the rate of obesity among primary school student as $4.8 \%$. In a study by Kutlu and Civi (15), the proportions of overweight and obese children were $7.7 \%$ and $1.9 \%$, respectively. In a study (7), 9\% of children were overweight and $4.1 \%$ were obese. In this study, the prevalence of overweight students was $8.4 \%$ and the obesity prevalence was $6.5 \%$. The study finding supported other study results conducted in Turkey. Recently, the increasing sedentary living conditions such as spending long periods by television and computer and using school transportation services may have caused the increase in the rate of obesity in children.

BMI increases as age increases. However, BMI means of males are a bit higher than those of females (16). In a survey, the prevalence of overweight males was $7.69 \%$, which was more than females (3.82\%). In a research, the obesity prevalence rates were $2.29 \%$ for females and $1.49 \%$ for males (17). In another study among students in Ankara province aged $6-12$ years, $1.9 \%$ of males and $3.7 \%$ of females were obese (14). The prevalence of overweight and obese people decreases as age increase and the highest prevalence rates are seen among the 6-10-year age group.

In studies attempting to find the causes of obesity, family history has always been among the risk factors. Eating habits of the family affect the weight of a person as does his or her genetics. As the number family members increases, obesity is less observed among children (18). A meaningful but inverse relationship is found between the existence of obese members in a family and obesity. In a study by Ceylan et al. this relationship was defined as a risk factor that raises the prevalence of obesity (19). The reason for this meaningful but inverse relationship could probably be considered as families who are bothered by their body weights try to maintain their children's body weights at normal levels.

In the study results analyzing the numbers of siblings, it was seen that the rate of overweight children who had one or two siblings was $70.8 \%$ and their obesity rate was $69.2 \%$. For those who had three or more siblings, the overweight rate was $14.9 \%$ and the obesity rate was $18.2 \%$. The obesity prevalence of children with one or two siblings was higher than those with more than two siblings $(\mathrm{P}<$ 0.05) (Table 3). This situation was assumed as a result of a lower income level and reduced food supply due to the higher number of family members.

In the study, no meaningful relationship between the obesity and the income level could be found, although the income level averages of the families were high ( $\mathrm{P}$ $>0.05$ ). In another study, an increase in socioeconomic levels was identified as a risk factor that enhanced obesity (20). The education levels of mothers and fathers and their occupations are important factors which can affect the income level. In a study aimed at adolescences, in areas with fewer college graduates, the obesity rates were higher due to unhealthy eating habits (21).

According to the results of the United States of America National Health and Nutrition Examination Survey III
(NHANES III), as the education level of mother and father increases, the prevalence of overweight and obese children decreases (22). When socio-demographic attributes were analyzed, a meaningful relationship between the education level of mother and obesity was determined ( $P$ $<0.05$ ) and no relation was found between the education level of father and obesity. This shows the possibility that the education level of mothers can be an effective factor on development and prevention of obesity (Table 3 ). The reason why the education level of father is not as effective as mothers may be due to the fact that mothers interact more with children. When working conditions of mothers and fathers were analyzed, no relationship between the occupation of mother and obesity could be identified; however, a meaningful relationship was found between the working conditions of father and obesity $(\mathrm{P}<$ $0.05)$. This relationship referred to the fact that children with working fathers were more obese (90.2\%) (Table 3).

In a study by Suzek et al. the obesity prevalence rates were high among children whose parents worked (23). This was probably due to malnutrition and fast food consumption. In the study, $83.2 \%$ of the students who thought that they had enough information about nutrition were diagnosed with obesity. This reveals that students are not really educated about this subject. In another study, the consumption levels of fat and high energy foods that result in obesity were higher in children who did not have education on the subject (24). In another study, the knowledge level of the patients that were admitted to an obesity clinic and patients that had education about the subject increased (25). It can be conceived that education is an important factor in preventing obesity.

There was a statistically meaningful relationship between fast food consumption and obesity (Table 3). Consumption of Turkish thin pizzas with spicy meat filling pitas, cakes/desserts, biscuits, pastries/cookies and chocolates/wafers were identified as foods that increase the risk of obesity. Therefore, children are more interested in these foods than healthy ones on a consistent basis. Besides, among beverages, black tea is another identified risk factor that increases obesity; Excess consumption of black tea with sugar contributes to weight gain. When the regularity of main meals of the students was analyzed, $88.7 \%$ had breakfast regularly, $76.8 \%$ had lunch regularly, and $93.4 \%$ had dinner regularly. In the study by Kutlu and Civi (15), these rates were identified as breakfast consumption (87.1\%), lunch consumption (93\%) and dinner consumption (94.9\%).

Foods such as fast food are low in nutritional value but high in energy, pure carbohydrate and fat. Most of the adolescents with irregular lunch habits consume foods with saturated fat and less vegetables and fruits. Fruits, vegetables and dairy products that are high in nutritional value are asserted to have preventative effects toward obesity (26). An inverse relationship between fruit consumption and overweight levels are shown in a study among the 5-8-year age groups (27). High-fiber, plant-based foods also 
have preventative effects against obesity (28). Pereira and Ludwig (29) have shown that high-fiber foods prevent children from becoming obese. Consumption of dairy products that are rich in calcium also prevents obesity (30).

Factors that affect the development of obesity in children show coherence with the factors asserted in literature. Today, obesity is one of the greatest health problems affecting children. This health concern may cause secondary health problems in the lives of children now or show up later as the children age. Obesity affects the lifetime of individuals and their quality of life; therefore, to prevent children who are the next generation and the basis of society against secondary health problems and to provide a high quality of life for them, obesity must be diagnosed in its early stages and precautions must be taken to solve this problem. School health services and school nurses are keys to addressing this problem that children are facing and ultimately preventing the onset of obesity.

The results in this study suggested that the behaviors that children learn will be shaped as their future life styles. A great number of these behaviors can be considered as risk factors for childhood overweight and obesity, such as poor eating habits, inadequate physical activity and wrong food habits. It is necessary to arrange training courses to teach sufficient and healthy nourishment and to instill a taste for physical activity. It is important to employ health nurses in schools.

The findings of the study were limited to the province of Zonguldak in Turkey.

In this research, to attain a successful conclusion, it was important to create a group of students from the school population. The school health services were able to control the health risks at every level and had an important role in helping students adopt healthy lifestyle behaviors (9). In addition to the regular role and function of the school nurses, due to different and complicated needs of the environment, they are serving and, as this environment are far medical solution opportunities, the frequency and the quality of their roles can change accordingly (10). Since they help find solutions, acting as advisors and offering efficient responses to problems arising during this process, school nurses are necessary in the fight against obesity.

\section{Authors' Contributions}

Tulay Kuzlu Ayyildiz participated in design and data collection. All authors read, performed statistical analysis, drafted and approved the final manuscript.

\section{References}

1. Kakinami L, Henderson M, Delvin EE, Levy E, O'Loughlin J, Lambert $\mathrm{M}$, et al. Association between different growth curve definitions of overweight and obesity and cardiometabolic risk in children. CMAJ. 2012;184(10):E539-50.

2. McCarthy HD. Measuring growth and obesity across childhood and adolescence. Proc Nutr Soc. 2014;73(2):210-7.

3. Yamane GK. Obesity in civilian adults: potential impact on eligibility for U.S. military enlistment. Mil Med. 2007;172(11):1160-5.
4. Sieber WK, Robinson CF, Birdsey J, Chen GX, Hitchcock EM, Lincoln JE, et al. Obesity and other risk factors: the National Survey of U.S. Long-Haul Truck Driver Health and Injury. Am J Ind Med. 2014;57(6):615-26.

5. Pi-Sunyer FX. The obesity epidemic: pathophysiology and consequences of obesity. Obes Res. 2002;10 Suppl 2:97S-104S.

6. Candido AP, Freitas SN, Machado-Coelho GL. Anthropometric measurements and obesity diagnosis in schoolchildren. Acta Paediatr. 2011;100(9):e120-4.

7. Obesity Prevention and Control Program of Turkey.. Ministry of health of Turkey general directorate of primary health care.Ankara: Kuban printing publishing; 2010.

8. Ramic E, Kapidzic-Durakovic S, Karic E, Batic-Mujanovic O, Alibasic E, Zildzic M. Influence of lifestyle on overweight and obesity in school-age children. Med Arh. 2009;63(5):280-3.

9. Wainwright $\mathrm{P}$, Thomas J, Jones $\mathrm{M}$. Health promotion and the role of the school nurse: a systematic review. J Adv Nurs. 2000;32(5):1083-91.

10. Vought-O'Sullivan V, Meehan NK, Havice PA, Pruitt RH. Continuing education: a national imperative for school nursing practice. J Sch Nurs. 2006;22(1):2-8.

11. SPSS Inc.. SPSS for Windows-Release 15.Chicago: SPSS Inc; 2008.

12. Günöz H, Saka N, Darendeliler F, Bundak R. Growth, development and endocrine. In: Cantez T editor. Child Health and Diseases.. Istanbul: Nobel Bookstores; 2003. pp. 111-4.

13. Saglam H, Tarim O. Prevalence and correlates of obesity in schoolchildren from the city of Bursa, Turkey. J Clin Res Pediatr Endocrinol. 2008;1(2):80-8.

14. Simșek E, Ulukol B, Berberoglu M, Gülnar SB, Adıyaman P, Ocal G. Obesity prevalence in a primary school and a high school in Ankara. J Ankara Univ Fac Med. 2005;58:163-6.

15. Kutlu R, Çivi S. The assessment of nutritional habits and body mass indexes of the students attending a private primary school. Firat Med J. 2009;14:18-24.

16. Papandreou D, Malindretos P, Rousso I. First body fat percentiles for 607 children from Thessaloniki-Northern Greece. Hippokratia. 2010;14(3):208-11.

17. Miqueleiz E, Lostao L, Ortega P, Santos JM, Astasio P, Regidor E. Trends in the prevalence of childhood overweight and obesity according to socioeconomic status: Spain, 1987-2007. Eur J Clin Nutr. 2014;68(2):209-14.

18. Kelishadi R, Haghdoost AA, Sadeghirad B, Khajehkazemi R. Trend in the prevalence of obesity and overweight among Iranian children and adolescents: a systematic review and meta-analysis. Nutrition. 2014;30(4):393-400.

19. Ceylan SS, Turan T. Obesity prevelance and influencing factors in a primary school students who were 11-14 years old.J Nurs Coll Atatürk Univ. 2008;11:76-84.

20. Raj M, Kumar RK. Obesity in children \& adolescents. Indian J Med Res. 2010;132:598-607.

21. Janssen I, Boyce WF, Simpson K, Pickett W. Influence of individual- and area-level measures of socioeconomic status on obesity, unhealthy eating, and physical inactivity in Canadian adolescents. Am J Clin Nutr. 2006;83(1):139-45.

22. Hanley AJ, Harris SB, Gittelsohn J, Wolever TM, Saksvig B, Zinman B. Overweight among children and adolescents in a Native $\mathrm{Ca}$ nadian community: prevalence and associated factors. Am J Clin Nutr. 2000;71(3):693-700.

23. Süzek H, Arı Z, Uyanık BS. The overweight and obesity prevalence in 6-15-years-old school children living in Muğla. Türk Biyokimya Dergisi. 2005;30(4):290-5.

24. Gitau G, Kimiywe J, Waudo J, Mbithe D. Effects of Nutrition Education on Nutrition Knowledge and Iron Status in Primary School Pupils of Gatanga District, Muranga Country, Kenya. Curr Rese Nutr Food Sci J. 2013;1(2):115-23.

25. Ades PA, Savage PD. The obesity paradox: perception vs knowledge. Mayo Clin Proc. 2010;85(2):112-4.

26. Skinner JD, Bounds W, Carruth BR, Ziegler P. Longitudinal calcium intake is negatively related to children's body fat indexes. $J$ Am Diet Assoc. 2003;103(12):1626-31.

27. Lin BH, Morrison RM. Higher fruit consumption linked with lower body mass index. Food Rev. 2002;25(3):28-32.

28. Berkey CS, Rockett HR, Field AE, Gillman MW, Frazier AL, Camar- 


\section{Ayyildiz TKet al.}

go CA, Jr., et al. Activity, dietary intake, and weight changes in a longitudinal study of preadolescent and adolescent boys and girls. Pediatrics. 2000;105(4):E56.

29. Pereira MA, Ludwig DS. Dietary fiber and body-weight regula- tion. Observations and mechanisms. Pediatr Clin North Am. 2001;48(4):969-80.

30. Zemel MB, Shi H, Greer B, Dirienzo D, Zemel PC. Regulation of adiposity by dietary calcium. FASEB J. 2000;14(9):1132-8. 